\title{
Contraceptive use among migrant women with a history of induced abortion in Finland
}

Heini Väisänen ${ }^{\mathrm{a}}$, Päivikki Koponen ${ }^{\mathrm{b}}$, Mika Gissler ${ }^{\mathrm{c}, \mathrm{d}, \mathrm{e}}$ and Osmo Kontula ${ }^{\mathrm{f}}$

aDepartment of Social Statistics and Demography, University of Southampton, Southampton, UK; 'bepartment of Public Health Solutions, National Institute for Health and Welfare (THL), Helsinki, Finland; 'Information Services Department, National Institute for Health and Welfare (THL), Helsinki, Finland; ${ }^{\mathrm{d}}$ Research Centre for Child Psychiatry, University of Turku, Turku, Finland; 'Department of Neurobiology, Care Services and Society, Karolinska Institute, Stockholm, Sweden; fPopulation Research Institute, Family Federation of Finland (Väestöliitto), Helsinki, Finland

\section{CONTACT}

Heini Väisänen, Department of Social Statistics and Demography, University of Southampton, Highfield Campus, University Road, Southampton SO17 1BJ, UK

h.e.vaisanen@soton.ac.uk

\section{Accepted Manuscript}

The Version of Record of this manuscript has been published on 25 June 2018 and is available in The European Journal of Contraception and Reproductive Health Care http://www.tandfonline.com/10.1080/13625187.2018.1483019 


\section{ABSTRACT}

Background: Women's contraceptive choices may change after an induced abortion, due to contraceptive counselling or a behavioural change prompted by the experience. The effect may vary between women; sociocultural background, for example, may affect their subsequent reproductive choices.

Objective: We examined whether women's current contraceptive use was differently associated with a history of induced abortion among immigrant groups in Finland (Russian, Kurdish and Somali) and the general Finnish population.

Methods: We analysed data from two surveys, the Migrant Health and Wellbeing study and the Health 2011 study, linked to the Finnish register of induced abortions. Propensity score weighted logistic regression was used to analyse the data.

Results: The likelihood of using contraceptives after an abortion varied depending on women's sociocultural background. A history of induced abortion increased contraceptive use among all groups, except Russian women, in whom there was no effect. The effect was particularly strong for Kurdish women.

Conclusion: Sociocultural background was an important determinant of post-abortion contraceptive use. Some immigrants may struggle to navigate the Finnish health care system due to language or literacy issues. Attention should be paid to improving access to family planning among these groups.

\section{KEYWORDS}

Family planning, Finland, induced abortion, migrant health, sexual and reproductive health 


\section{Introduction}

Contraceptive non-use or failure may lead to unintended pregnancy. Around half of such pregnancies are terminated [1]. Women's contraceptive choices may change after an induced abortion, for instance due to post-abortion contraceptive counselling [2] or because the experience prompted a behavioural change [3]. For example, in Helsinki 75\% of women adopt a reliable contraceptive method after an abortion [4] and in many European countries those with a history of abortion are more likely to use contraceptives than those without [3,5], or to change methods after an abortion [6].

The effect of abortion on contraceptive use may vary depending on the woman's sociocultural background, which is important as it influences sexual and reproductive behaviours including abortion and contraceptive use [3,7]. Many religions control sexuality and restrict family planning use. For example, depending on the denomination of Christianity, contraceptive use might either be fully prohibited or left to the discretion of the couple [8]. Similarly, depending on the interpretation of Islam, contraception might be restricted to a small selection of traditional methods, or all reversible methods might be allowed [8]. Both religions tend to prohibit abortion in most situations [8].

Sociocultural background may affect abortion behaviour and contraceptive use via the cultural values and practices of the country of origin. Abortions were common in Russia and in the former Soviet Union due to the lack of reliable contraceptive methods and the belief that contraceptive use was dangerous [9-12]. In Estonia, differences in sociocultural backgrounds might have influenced post-abortion contraceptive use in Russian- and Estonian-speaking women: while previous abortion was associated with an increased risk of not using a method among Russian-speaking women, the opposite was true for Estonian-speaking women [13]. In Finland, migrants of Russian origin have a higher age-specific abortion rate compared with the general population [14]. Their post-abortion contraceptive use has, however, not been previously studied.

Many Kurdish migrants in Finland come from Iran or Iraq. In Iran, abortion is morally condemned by the religious authorities and is legal only on very restricted grounds [15]. Nevertheless, in 2013, 31\% of Iranian women reported an unwanted pregnancy [16], 
and 17\% reported having had an abortion [17]. Abortion rates in Iraq are not known, but abortion legislation is very strict [18].

Abortion statistics for Somalia are not available, but abortion is only allowed to preserve a woman's health, resulting in illegal, unsafe abortions that are a substantial cause of maternal mortality $[19,20]$. A qualitative study in the USA suggested that young, sexually active immigrant Somali women may have abortions due to lack of contraceptive knowledge, as contraception is a taboo subject in many families [21]. Somali women in Finland may be more aware of contraception than their counterparts in the USA, but still need to negotiate its use with their partner and religious beliefs [22].

Sociocultural background is not the only factor associated with abortion and contraceptive use. Migrant women may be less likely to use contraceptives compared with native women, for example due to literacy or language issues, and/or lower socioeconomic position causing difficulties within the health care system [23]. Women from disadvantaged backgrounds [24], with low education or no partner [5,25], report low contraceptive use and have a higher likelihood of experiencing an abortion [26].

\section{Finnish context}

Migration to Finland has increased rapidly since the 1990s. In 2012, 5.3\% of the population was foreign-born [27]. The largest migrant groups are those born in Russia or the former Soviet Union, Sweden, Estonia, Somalia, Iraq, China and Thailand [27]. Many Somali and Kurdish migrants are refugees [28].

In Finland, there are no substantial limitations in obtaining abortions within the first trimester [29]. Abortion rates in Finland are lower than in many other Western countries [30] and are the lowest in the Nordic countries [31]. In 2011, the abortion rate was 9/1000 women of reproductive age [32]. Family planning services are offered in all municipalities and the first 3 months of oral contraceptives or the first intrauterine device (IUD) are often free of charge [33,34]. 


\section{Aim of the study}

The aim of the study was to compare the association between having had at least one abortion and current contraceptive use among Kurdish, Somali and Russian originmigrants and the general population in Finland. We examined whether women's sociocultural background interacted with the likelihood of adopting a modern contraceptive method after an abortion. Our study was designed to examine the importance of sociocultural background: we included women from different backgrounds who lived in the same context at the time of experiencing an abortion. Thus, factors other than sociocultural factors affecting contraceptive uptake after abortion, such as availability of contraceptives and post-abortion counselling, were standardised. Although we know that in Finland not using contraceptives prior to abortion was more common among migrant women from Iran, Iraq or Afghanistan (54\%) and among women from the former Soviet Union and Russia (55\%) than among Finnish women (35\%) seeking abortion [14], there is a lack of research examining contraceptive use after an abortion.

\section{Methods}

\section{Data collection and participants}

We used data from three sources: two health surveys (the Migrant Health and Wellbeing study and the Health 2011 study) combined with the Finnish register of induced abortions.

The Migrant Health and Wellbeing study 2010-2012 (Maamu) surveyed migrants of Somali, Russian and Kurdish origin who had resided in Finland for at least 1 year. Participants were recruited from six municipalities with a high number of migrants: Helsinki, Espoo and Vantaa from the capital metropolitan area, and Turku, Tampere and Vaasa from southern and western Finland. At that time, 93\% of Somali, 67\% of Kurdish and $47 \%$ of Russian origin migrants lived in these municipalities. Selection criteria for the Russian group was Russia or the former Soviet Union as the country of birth and Russian or Finnish as the native language; the Somali group included those born in Somalia; the Kurdish group included those born in Iraq or Iran with the native language 
of Kurdish. Participants aged 18-64 ( $n=1000)$ were sampled from each of the migrant groups, using stratified random sampling by municipality and group. In this sample, 622 in the Russian, 531 in the Somali and 426 in the Kurdish group were women. Overall, $70 \%$ of the Russian, $51 \%$ of the Somali and $63 \%$ of the Kurdish population participated in the survey $[28,35]$. A comparison group of the general Finnish population was selected from the national sample of the Health 2011 study [36] including all sampled individuals of the same age in the six municipalities $(n=2276)$.

Both surveys were linked to the Finnish register of induced abortions. All physicians performing abortions in Finland are required by law to register the event [37]. According to a recent evaluation, the register captures 97\% of abortions [38]. The register provides reliable information about abortions, which are usually severely underreported in surveys [39]. All non-pregnant women aged 18-44 of Somali $(n=124)$, Russian ( $n=183)$ and Kurdish ( $n=164)$ origin and of the general female population ( $n=187)$ were included in our study.

The National Institute for Health and Welfare obtained ethical approval for the study, including approval to link register and survey data, from the Coordinating Ethical Committee of the Helsinki and Uusimaa Hospital Region. The register linkage was described in the participants' written informed consent. Ethical approval to analyse the data for this study was also obtained from the University of Southampton Ethics Board.

\section{Measures}

Our outcome variable was current contraceptive use. Those using any of the following methods were counted as a contraceptive user: oral contraceptive, ring, patch, IUD, sterilisation or condom.

The main explanatory variable was history of induced abortion in Finland. We put women into 'never abortion' and 'ever abortion' groups based on data from the abortion register. Although women were also asked to report their abortion experiences in the two surveys, we did not include this information. First, abortions are usually underreported [39]. Thus, we would have had complete information regarding abortions obtained in Finland (from the register), but incomplete information regarding abortions obtained elsewhere (self-reported). Second, since women were not asked to self-report 
the timing of their abortion, we would not have been able to control for time since abortion for the self-reported variable. Third, an abortion obtained in Finland or elsewhere may have a different effect on contraceptive behaviour, particularly if the abortion was illegal or unsafe. In these contexts, women do not receive post-abortion contraceptive counselling [40] and many suffer from adverse health consequences [41].

Other explanatory variables from the surveys were education (less than upper secondary vs at least upper secondary), age, parity (number of live births) and relationship status (single, married, cohabiting or separated/divorced/widowed). For those who had ever had an abortion, we also included years since the most recent abortion took place, and whether the women used modern contraceptives before their most recent abortion (the latter based on self-reporting before the procedure) from the abortion register. Previous contraceptive use was not recorded for those who had never had an abortion. For immigrant women we included an indicator of whether they migrated to Finland before age 16, to indicate their exposure to the Finnish education system (it is compulsory to go to school until age 16). This is important because sexuality education is delivered in all schools, and because schools are important places for socialisation. We also controlled for self-reported religion (Muslim vs other) among migrants. Information about religion was not collected for the general population, but around $78 \%$ of the Finnish population in 2011 were Lutheran or Greek Orthodox [42].

The outcome variable and most explanatory variables were extracted from the two surveys. The exceptions are the history of induced abortion, time since last abortion and contraceptive use before abortion variables, which we obtained from the register of induced abortions.

\section{Analysis}

Our aim was to estimate whether having an abortion was associated with current contraceptive use, while controlling for a range of adjustment variables.

Results from a standard logistic regression regarding the effect of abortion may be biased if some characteristics are associated with both the likelihood of experiencing an abortion and using contraception (i.e. a selection effect). Therefore, we analysed these data using propensity score weighted logistic regression [43-45]. 
Propensity score is the probability of having an abortion given a set of observed baseline characteristics. The score can be used to weight our observational study so that it to an extent mimics a randomised controlled trial: it balances the sample so that those who had an abortion, and those who did not, have a similar distribution of baseline characteristics [45]. The propensity score is a predicted probability from a logistic regression model, where the baseline characteristics predict the likelihood of having an abortion.

We calculated average treatment effect on the treated (ATT) weights [44], which leave the group that experienced an abortion unaltered. Those who had never had an abortion were weighted with propensity scores to cancel the selection effect by making the baseline characteristics of this group similar to those of the abortion group. ATT weights estimate the average effect of having an abortion on current contraceptive use among those who have a high propensity for abortion. In other words, if a woman who had had an abortion had not conceived at that time (and hence avoided the abortion), would her current contraceptive use have been any different [46]. The appendix provides a technical explanation of the methods used.

Inverse sampling probability weights were applied and finite populations were accounted for in all analyses to correct for non-response and different sampling probabilities. The propensity score weights were multiplied by the sampling weights.

We first calculated the propensity score, which is the probability of having an abortion using birth cohort, immigrant background, religion, age moved to Finland and education as baseline variables (Appendix Table 1). We used these propensities as weights among the 'never abortion' group. We confirmed that the baseline characteristics were balanced with respect to history of induced abortion, i.e. the means of the baseline characteristics were similar in both groups (ever abortion vs never abortion) (Appendix Table 2). These weights were used in a logistic regression model estimating the likelihood of being a current contraceptive user. In this model we included the baseline characteristics, current partnership status, years since last abortion, number of live births and interaction between abortion and immigrant background. We conducted two sets of analyses: standard logistic regression and propensity score weighted regression, to compare whether controlling for the selection effect had an impact on the results. 
Finally, to study whether contraceptive use before the abortion might explain our results, we analysed current contraceptive use of women who had ever had an abortion, controlling for contraceptive use before their latest abortion. Propensity scores were not needed here, as they control for selection into who had an abortion, and all women in this model had had one.

\section{Results}

\section{Descriptive statistics}

Russian (40\%) and Kurdish (26\%) women had more often experienced an abortion compared with women in the general population (17\%) or with Somali women (11\%) (Table 1). Contraceptive use was most prevalent among the general population (70\%), followed by Russian (56\%), Kurdish (51\%) and Somali (17\%) women. Somali and Kurdish populations were younger than the Russian and general populations. Somali women had the highest average number of children at the time of the interview (3.17) followed by Kurdish (2.05), the general population (0.95) and Russian women (0.90). Somali women were often married, whereas the general population cohabited more compared with the immigrant groups (Table 1).

While women with a history of induced abortion more often used contraceptives than women with no such history in the general, Somali and Kurdish populations, the opposite was true among Russian women (Table 2). However, the wide confidence intervals (CIs) suggest these differences were not significant.

\section{Multivariate analysis}

The interaction between abortion and immigrant background was significant at the $10 \%$ level in the joint Wald test in the standard model $(p=0.066)$ and in the propensity score weighted model ( $p=0.052$ ) (Table 3). Figure 1a shows the marginal probabilities of contraceptive use calculated from the standard model and Figure $1 \mathrm{~b}$ from the propensity score weighted model. While the results are similar in both models, controlling for (some) selection effects reduced the differences between the migrant groups. Among the general and Kurdish populations, women with a history of abortion were more likely to use contraception in the standard model (Figure 1a). In the propensity score weighted 
model, Kurdish women were the only group for which the CIs do not overlap between the 'never abortion’ and 'ever abortion’ groups (Figure 1b). Among Russian women, the point estimates in the weighted model were very close to each other, suggesting that while for the other groups history of abortion may increase the likelihood of contraceptive use, for Russian women that experience makes no difference (Figure 1b).

Education, religion, or age at the time of immigration were not statistically significantly associated with contraceptive use. Age and time since having an abortion were negatively associated with the odds of using contraceptives - although the latter was not significant in the propensity score weighted model. Married and cohabiting women were more likely than women without a partner to use contraceptives, perhaps reflecting frequency of sexual activity.

Table 4 shows the odds of using modern contraceptives among women with a history of induced abortion. The interaction between migrant background and previous contraceptive use was significant at the $10 \%$ level in the joint Wald test ( $p=0.062)$. While in all other groups having used contraceptives before the most recent abortion was positively associated with also using them after the abortion, this was not the case for Somali women. Their predicted probability of using contraception was 30\% among those without prior use compared with 9\% among those with prior use (Table 5). However, due to the small sample size $(n=88)$ these results are only indicative.

\section{Discussion}

\section{Findings and interpretation}

We examined whether women's sociocultural background interacts with the likelihood of adopting a modern contraceptive method after an abortion and found that there were indeed differences. The general population was more likely to use contraceptives compared with migrants. Women from immigrant backgrounds may find it challenging to understand the Finnish health care system, particularly if they lack the relevant language or literacy skills. Access to health care services should be improved among these groups. Negative attitudes towards contraception, desire for a large family, religious reasons, or spousal disagreement over family planning methods may also reduce contraceptive use among some migrants [11,22,47]. 
Descriptive statistics suggested that the effect of having had an abortion on current contraceptive use among Russian women may decrease the likelihood of using contraceptives, as has been shown previously [13]. However, after controlling for selection, both groups had similar levels of contraceptive use. Thus, selection might have been behind the previous results. Some women of Russian origin may believe that contraceptive use is dangerous and therefore prefer using abortions to control family size [11].

The association between having had an abortion and increased current contraceptive use was particularly strong among Kurdish women. While those without a history of induced abortion had a relatively low contraceptive prevalence, those who had had an abortion had a similar contraceptive prevalence to that of the general population. This may suggest that the provision of post-abortion contraceptive counselling has an important effect on this group.

Among women with a history of induced abortion, having used contraceptives before the termination increased the likelihood of current contraceptive use, apart from Somali women. Fewer than one in 10 Somali women who had used contraceptives prior to the termination adopted a method after an abortion, compared with 30\% among those who did not use a method before the abortion. These women may benefit from tailored postabortion counselling that takes into account their sociocultural background and informs them about the available methods and their possible side effects $[2,7,21]$.

\section{Strengths and weaknesses of the study}

The strengths of the study include reliable abortion data that do not suffer from underreporting, which is common in surveys [39]. Not many datasets allow for a reliable comparison of abortion and contraceptive use between the general and immigrant populations. Combining survey and register data is one of the main strengths of this study.

The study had some limitations. Propensity score weighted regressions have been criticised for having potential bias and for their standard errors becoming too small [48]. We show both standard and propensity score weighted results. There were no large differences between the two, which may indicate that selection was not important or 
that the model creating the propensity scores omitted important variables. Therefore, we are cautious about interpreting these results in a strictly causal manner. We also had no information about pregnancy intentions. Some women may not use contraceptives because they are trying to conceive or are ambivalent about their pregnancy desires $[25,49]$. Moreover, the data on the use of contraceptives before and after abortion were self-reported, which may result in misreporting method use. This limitation applies to all studies using survey data. Finally, the sample size was relatively small, which is common in studies of immigrant populations but may compromise the statistical power of the analysis.

\section{Differences and similarities in relation to other studies}

Few studies have been able to investigate contraceptive use and abortion using reliable data in a single study, because reliable data on abortion, such as medical registers, often do not include comprehensive information about contraceptive use. Our study contributes to these gaps in the literature using an innovative research design. There is also a shortage of previous research examining contraceptive use after an abortion.

Similarly to previous studies $[3,8]$, differences in contraceptive use patterns were found depending on sociocultural background. However, as discussed above, we did not find that having had an abortion decreased the likelihood of current contraceptive use among Russian women, as a previous study found [13].

\section{Open questions and future research}

Future research is needed for better understanding of issues specific to Somali women, to reduce the barriers in using a contraceptive method before and after an abortion. The reasons why contraceptive uptake was particularly high among Kurdish women after an abortion require more research. Data on pregnancy intentions should be collected so that women not using contraceptives because they are trying to conceive could be excluded from the sample in future studies of contraceptive use. 


\section{Recommendation for clinicians and policy-makers}

These results are of interest to policy-makers and health care professionals who wish to improve the sexual and reproductive health of the immigrant populations in Finland. Our results show that the likelihood of using contraception after an abortion differs between each immigrant group and the general population, and that these groups may benefit from different kinds of contraceptive counselling after abortion and easier access to services.

\section{Acknowledgements}

The authors would like to thank Minna Säävälä for her contributions at the early stages of the manuscript.

\section{Disclosure statement}

The authors have no conflicts of interest to declare.

\section{Funding}

This research received no specific grant from any funding agency in the public, commercial or not-for-profit sectors. The Maamu data collection was funded by the Social Insurance Institution of Finland (KELA), European Social Fund (ESF) and the Finnish Work Environment Fund. 


\section{References}

[1] Sedgh G, Singh S, Hussain R. Intended and unintended pregnancies worldwide in 2012 and recent trends. Stud Fam Plann. 2014;45:301-314.

[2] Schunmann C, Glasier A. Specialist contraceptive counselling and provision after termination of pregnancy improves uptake of long-acting methods but does not prevent repeat abortion: a randomized trial. Hum Reprod. 2006;21:2296-2303.

[3] Moreau C, Trussell J, Desfreres J, et al. Patterns of contraceptive use before and after an abortion: results from a nationally representative survey of women undergoing an abortion in France. Contraception. 2010;82:337-344.

[4] Heikinheimo O, Gissler M, Suhonen S. Can the outcome of the next pregnancy be predicted at the time of induced abortion? Hum Reprod. 2009;24:820-826.

[5] Spinelli A, Talamanca IF, Lauria L. Patterns of contraceptive use in 5 European countries. European Study Group on Infertility and Subfecundity. Am J Public Health. 2000;90:1403-1408.

[6] Bianchi-Demicheli F, Perrin E, Bianchi PG, et al. Contraceptive practice before and after termination of pregnancy: a prospective study. Contraception. 2003;67:107-113.

[7] Jones RK, Darroch JE, Henshaw SK. Contraceptive use among U.S. women having abortions in 2000-2001. Perspect Sex Reprod Health. 2002;34:294-303.

[8] Srikanthan A, Reid RL. Religious and cultural influences on contraception. J Obstet Gynaecol Can. 2008;30:129-137.

[9] Haavio-Mannila E, Kontula O, Mäkinen M. Sexual trends in the Baltic Sea area. Helsinki: Population Research Institute, Family Federation of Finland 2003.

[10] Ihamäki K (2012). Russian roulette - the barriers and needs of family planning among adolescents in St Petersburg and Riga [in Finnish]. Available from: http://urn.fi/URN:ISBN:978-951-29-4874-1 (accessed 25 May 2018).

[11] Regushevskaya E, Dubikaytis T, Nikula M, et al. Contraceptive use and abortion among women of reproductive age in St. Petersburg, Russia. Perspect Sex Reprod Health. 2009;41:51-58.

[12] Remennick LI, Amir D, Elimelech Y, et al. Family planning practices and attitudes among former Soviet new immigrant women in Israel. Soc Sci Med. 1995;41:569-577. 
[13] Laanpere M, Rahu K, Part K, et al. Ethnic differences in factors associated with the use of contraception among 20- to 44-year-old women in Estonia and St. Petersburg, Russia. Contraception. 2012;86:132-140.

[14] Malin M, Gissler M. Induced abortions among immigrant women in Finland. Finn J Ethn Migr. 2008;3:2-12.

[15] Hosseini-Chavoshi M, Abbasi-Shavazi MJ, Glazebrook D, et al. Social and psychological consequences of abortion in Iran. Int J Gynaecol Obstet. 2012;118(Suppl. 2):S172-S177.

[16] Motlaq ME, Eslami M, Yazdanpanah M, et al. Contraceptive use and unmet need for family planning in Iran. Int J Gynaecol Obstet. 2013;121:157-161.

[17] Ranji A. Induced abortion in Iran: prevalence, reasons, and consequences. J Midwifery Women’s Health. 2012;57:482-488.

[18] Center for Reproductive Rights (2018). The world's abortion laws. Available from: http://worldabortionlaws.com/ (accessed 25 May 2018).

[19] Gure F, Dahir MK, Yusuf M, et al. Emergency contraception in post-conflict Somalia: an assessment of awareness and perceptions of need. Stud Fam Plann. 2016;47:69-81.

[20] Sorbye IK (2009). A situation analysis of reproductive health in Somalia. Available from: www.unicef.org/somalia/SOM_resources_finalRHSanalysis.pdf (accessed 25 May 2018).

[21] Pavlish CL, Noor S, Brandt J. Somali immigrant women and the American health care system: discordant beliefs, divergent expectations, and silent worries. Soc Sci Med. 2010;71:353-361.

[22] Degni DF, Koivusilta L, Ojanlatva A. Attitudes towards and perceptions about contraceptive use among married refugee women of Somali descent living in Finland. Eur J Contracept Reprod Health Care. 2006;11:190-196.

[23] Derose KP, Escarce JJ, Lurie N. Immigrants and health care: sources of vulnerability. Health Aff. 2007;26:1258-1268.

[24] Martinez G, Copen CE, Abma JC. Teenagers in the United States: sexual activity, contraceptive use, and childbearing, 2006-2010 national survey of family growth. Vital Health Stat 23. 2011;31:1-35.

[25] Frost JJ, Singh S, Finer LB. Factors associated with contraceptive use and nonuse, United States, 2004. Perspect Sex Reprod Health. 2007;39:90-99. 
[26] Väisänen H. The association between education and induced abortion for three cohorts of adults in Finland. Popul Stud (Camb). 2015;69:373-388.

[27] Statistics Finland (2013). Population structure 2012. Available from: www.stat.fi/til/vaerak/2012/01/vaerak_2012_01_2013-09-27_tie_001_en.html (accessed 28 November 2016).

[28] Castaneda AE, Rask S, Koponen P, et al. Migrant health and wellbeing - study of the Russian, Somali and Kurdish populations in Finland [in Finnish]. Available from: www.julkari.fi/handle/10024/90907 (accessed 28 November 2016).

[29] Knudsen LB, Gissler M, Bender SS, et al. Induced abortion in the Nordic countries: special emphasis on young women. Acta Obstet Gynecol Scand. 2003;82:257-268.

[30] Denisov BP, Sakevich VI, Jasilioniene A. Divergent trends in abortion and birth control practices in Belarus, Russia and Ukraine. PLoS One. 2012;7:e49986.

[31] Gissler M, Heino A (2011). Induced abortions in the Nordic countries 2009. Available from: http://urn.fi/URN:NBN:fi-fe201205085255(accessed 25 May 2018).

[32] Heino A, Gissler M (2012). Induced abortions 2011 [in Finnish]. Available from: http://urn.fi/URN:NBN:fi-fe201301221636 (accessed 3 December 2012).

[33] Hemminki E, Sihvo S, Koponen P, et al. Quality of contraceptive services in Finland. Qual Saf Health Care. 1997;6:62-68.

[34] Sannisto T, Kosunen E. Provision of contraception: a survey among primary care physicians in Finland. Acta Obstet Gynecol Scand. 2010;89:636-645.

[35] National Institute for Health and Welfare (2014). Background of the Maamu study. Available from: https://thl.fi/en/web/thlfi-en/research-andexpertwork/population-studies/migrant-health-and-wellbeing-study-maamu/background-of-the-maamu-study (accessed 26 February 2018).

[36] Lundqvist A, Mäki-Opas T. Health 2011 survey - methods. Available from: www.julkari.fi/handle/10024/130780 (accessed 28 November 2016).

[37] National Institute for Health and Welfare (2015). Register of induced abortions. Available from: www.thl.fi/en/web/thlfi-en/statistics/information-onstatistics/register-descriptions/register-of-induced-abortions (accessed 26 September 2015). 
[38] Heino A, Niinimäki M, Mentula M, et al. How reliable are health registers? Registration of induced abortions and sterilizations in Finland. Inform Health Soc Care. 2018;43:310-319.

[39] Jones RK, Kost K. Underreporting of induced and spontaneous abortion in the United States: an analysis of the 2002 National Survey of Family Growth. Stud Fam Plann. 2007;38:187-197.

[40] Rogers C, Dantas JAR. Access to contraception and sexual and reproductive health information post-abortion: a systematic review of literature from low- and middle-income countries. J Fam Plann Reprod Health Care. 2017;43:309-318.

[41] Shrivastava SR, Shrivastava PS, Ramasamy J. Unsafe abortion: a cruel way of birth control. Afr Health Sci. 2014;14:487-488.

[42] Statistics Finland (2014). Population structure. Appendix table 2: religious affiliation of the population, share of population, \% 1950-2013. Available from: www.stat.fi/til/vaerak/2013/vaerak_2013_2014-03-21_tau_002_en.html (accessed 10 October 2017).

[43] DuGoff EH, Schuler M, Stuart EA. Generalizing observational study results: applying propensity score methods to complex surveys. Health Serv Res. 2014;49:284-303.

[44] Morgan SL, Todd JJ. A diagnostic routine for the detection of consequential heterogeneity of causal effects. Sociol Methodol. 2008;38:231-282.

[45] Austin PC. An introduction to propensity score methods for reducing the effects of confounding in observational studies. Multivariate Behav Res. 2011;46:399424.

[46] Su JH, Dunifon R, Sassler S. Better for baby? The retreat from mid-pregnancy marriage and implications for parenting and child well-being. Demography. 2015;52:1167-1194.

[47] Degni F, Mazengo C, Vaskilampi T, et al. Religious beliefs prevailing among Somali men living in Finland regarding the use of the condom by men and that of other forms of contraception by women. Eur J Contracept Reprod Health Care. 2008;13:298-303.

[48] Freedman DA, Berk RA. Weighting regressions by propensity scores. Eval Rev. 2008;32:392-409. 
[49] Jones RK, Tapales A, Lindberg LD, et al. Using longitudinal data to understand changes in consistent contraceptive use. Perspect Sex Reprod Health.

2015;47:131-139. 
Table 1. Distribution of sociodemographic characteristics by immigrant background (unweighted $n=658$ ).

\begin{tabular}{|c|c|c|c|c|}
\hline Characteristic & $\begin{array}{l}\text { General population } \\
(n=187)\end{array}$ & $\begin{array}{l}\text { Russian } \\
(n=183)\end{array}$ & $\begin{array}{l}\text { Somali } \\
(n=124)\end{array}$ & $\begin{array}{l}\text { Kurdish } \\
(n=164)\end{array}$ \\
\hline Ever had an abortion, \% & 16.7 & 39.5 & 11.0 & 25.5 \\
\hline Use of contraception, \% & 70.4 & 56.0 & 17.1 & 51.0 \\
\hline \multicolumn{5}{|l|}{ Education, \%a } \\
\hline Less than upper secondary & 22.8 & 17.0 & 78.8 & 56.8 \\
\hline At least upper secondary & 77.2 & 83.0 & 21.2 & 43.2 \\
\hline \multicolumn{5}{|l|}{ Age, $\%^{\mathrm{a}}$} \\
\hline $18-24$ & 12.0 & 19.4 & 34.1 & 20.1 \\
\hline $25-29$ & 11.1 & 27.3 & 18.4 & 19.5 \\
\hline $30-34$ & 28.8 & 14.0 & 17.1 & 21.1 \\
\hline $35-39$ & 18.8 & 22.7 & 15.4 & 17.9 \\
\hline $40-44$ & 29.3 & 16.5 & 15.0 & 21.5 \\
\hline Mean parity, $n$ & 0.95 & 0.90 & 3.17 & 2.05 \\
\hline \multicolumn{5}{|l|}{ Relationship status, $\%^{\mathrm{a}}$} \\
\hline Single & 29.5 & 24.9 & 20.3 & 21.9 \\
\hline Married & 36.5 & 43.5 & 65.4 & 52.0 \\
\hline Cohabiting & 27.8 & 16.1 & 1.4 & 12.3 \\
\hline Separated/divorced/widowed & 6.2 & 15.5 & 12.9 & 13.7 \\
\hline Mean no. of years since abortion ${ }^{\mathrm{b}}$ & 5.4 & 3.7 & 2.7 & 2.7 \\
\hline Used contraceptives before abortion, \% ${ }^{\mathrm{b}}$ & 65.0 & 52.3 & 62.7 & 49.3 \\
\hline Immigrated after age $16, \%^{c}$ & $\mathrm{n} / \mathrm{a}$ & 65.7 & 50.2 & 75.7 \\
\hline Muslim faith, $\%^{\mathrm{c}}$ & $\mathrm{n} / \mathrm{a}$ & 0.03 & 95.3 & 60.5 \\
\hline
\end{tabular}

${ }^{\mathrm{a}}$ Column percentages total $100 \%$.

${ }^{\mathrm{b}}$ Includes only those who had ever had an abortion.

'Includes only migrant women.

n/a, Not available. 
Table 2. Percentage of women using contraceptives by immigrant background and history of induced abortion.

\begin{tabular}{lllll}
\hline Group & No abortion & $95 \%$ CI & Abortion & $95 \%$ CI \\
\hline General population & 68.6 & $60.7,76.5$ & 79.2 & $65.4,93.0$ \\
Russian & 61.9 & $51.8,71.9$ & 46.9 & $34.2,59.6$ \\
Somali & 15.2 & $7.8,22.6$ & 31.2 & $2.7,59.8$ \\
Kurdish & 45.3 & $36.9,53.7$ & 66.7 & $53.5,79.9$ \\
\hline
\end{tabular}


Table 3. Likelihood of using any form of modern contraception: logistic regression with and without propensity score weights ( $n=609)$.

\begin{tabular}{|c|c|c|c|}
\hline \multirow[t]{2}{*}{ Variable } & \multirow[t]{2}{*}{ Category } & \multicolumn{2}{|c|}{ Odds ratio } \\
\hline & & Standard & ATT \\
\hline \multirow[t]{2}{*}{ History of induced abortion } & Never abortion (ref.) & 1.00 & 1.00 \\
\hline & Ever abortion & $10.2^{*}$ & $7.30^{*}$ \\
\hline \multirow[t]{4}{*}{ Group } & General population (ref.) & 1.00 & 1.00 \\
\hline & Russian & $0.45 *$ & $0.41^{\dagger}$ \\
\hline & Somali & $0.04 * * *$ & $0.04 * * *$ \\
\hline & Kurdish & $0.28 * *$ & $0.25^{*}$ \\
\hline \multirow{3}{*}{$\begin{array}{l}\text { Interaction: immigrant group } \\
\text { and abortion }\end{array}$} & Ever abortion x Russian & $0.15^{* a}$ & $0.15^{* b}$ \\
\hline & Ever abortion $\mathrm{x}$ Somali & 0.47 & 0.52 \\
\hline & Ever abortion x Kurdish & 0.45 & 0.62 \\
\hline Age & & $0.94 * *$ & $0.92 * *$ \\
\hline \multirow[t]{2}{*}{ Education } & $\begin{array}{l}\text { Less than upper secondary } \\
\text { education (ref.) }\end{array}$ & 1.00 & 1.00 \\
\hline & $\begin{array}{l}\text { At least upper secondary } \\
\text { education }\end{array}$ & 1.07 & 0.95 \\
\hline Birth history & Parity & $1.21^{* *}$ & 1.07 \\
\hline \multirow[t]{4}{*}{ Relationship status } & Single (ref.) & 1.00 & 1.00 \\
\hline & Married & $2.89 * * *$ & $5.18^{* * *}$ \\
\hline & Cohabiting & $3.49 * * *$ & $6.80^{* * *}$ \\
\hline & Separated/divorced/widowed & 1.02 & 1.33 \\
\hline \multirow[t]{2}{*}{ Religion } & Native or other faith (ref.) & 1.00 & 1.00 \\
\hline & Muslim & 0.75 & 0.65 \\
\hline \multirow[t]{2}{*}{ Migration history } & Native or moved before age 16 & 1.00 & 1.00 \\
\hline & Moved after age 16 & 1.20 & 1.29 \\
\hline Years since abortion & & $0.90 *$ & 0.92 \\
\hline
\end{tabular}

$\dagger p<0.1,{ }^{*} p<0.05,{ }^{* *} p<0.01,{ }^{* * *} p<0.001$.

Interaction: ${ }^{\mathrm{a}} p=0.066,{ }^{\mathrm{b}}$ Interaction $p=0.052$. 
Table 4. Likelihood of using any form of modern contraception among those who had an abortion: logistic regression with and without propensity score weights $(n=88)$.

\begin{tabular}{|c|c|c|}
\hline Variable & Category & $\begin{array}{l}\text { Odds } \\
\text { ratio }\end{array}$ \\
\hline \multirow{2}{*}{$\begin{array}{l}\text { Contraceptive use preceding most recent } \\
\text { abortion }\end{array}$} & Did not use (ref.) & 1.00 \\
\hline & Used a method & 4.61 \\
\hline \multirow[t]{4}{*}{ Group } & General population (ref.) & 1.00 \\
\hline & Russian & $0.01^{*}$ \\
\hline & Somali & $0.04^{\dagger}$ \\
\hline & Kurdish & 0.12 \\
\hline \multirow{3}{*}{$\begin{array}{l}\text { Interaction: immigrant group and } \\
\text { contraceptive use }^{\mathrm{a}}\end{array}$} & Used a method x Russian & 1.25 \\
\hline & Used a method x Somali & $0.02^{\dagger}$ \\
\hline & Used a method x Kurdish & 0.64 \\
\hline Age & & $0.79 * *$ \\
\hline \multirow[t]{2}{*}{ Education } & Less than upper secondary education (ref.) & 1.00 \\
\hline & At least upper secondary education & 1.01 \\
\hline Birth history & Parity & 0.86 \\
\hline \multirow[t]{4}{*}{ Relationship status } & Single & 1.00 \\
\hline & Married & $57.4^{* *}$ \\
\hline & Cohabiting & $97.9 * *$ \\
\hline & Separated/divorced/widowed & 5.60 \\
\hline \multirow[t]{2}{*}{ Religion } & General population or other faith (ref.) & 1.00 \\
\hline & Muslim & 0.43 \\
\hline \multirow[t]{2}{*}{ Migration history } & Native or moved before age 16 & 1.00 \\
\hline & Moved after age 16 & $4.11^{*}$ \\
\hline Years since abortion & & 0.98 \\
\hline
\end{tabular}

$\dagger p<0.1,{ }^{*} p<0.05,{ }^{* *} p<0.01$.

(a) Sig. of the interaction $p=0.062$. 
Table 5. Predicted probabilities of current contraceptive use by prior contraceptive use based on model in Table 4 ( $n=88)$.

\begin{tabular}{lll}
\hline Group & Did not use $(95 \% \mathrm{CI})$ & Used $(95 \% \mathrm{CI})$ \\
\hline General population & $0.71(0.37,1.04)$ & $0.84(0.69,1.00)$ \\
Russian & $0.16(0.03,0.29)$ & $0.36(0.16,0.56)$ \\
Somali & $0.30(-0.02,0.61)$ & $0.09(-0.03,0.21)$ \\
Kurdish & $0.44(0.19,0.69)$ & $0.58(0.37,0.79)$ \\
\hline
\end{tabular}


Figure 1. Predicted probabilities of using any modern contraception by history of induced abortion and immigrant group from (A)standard logistic regression (sig. of the interaction effect $\mathrm{p}=0.066$ ) and $(\mathbf{B})$ propensity score weighted regression (sig. of the interaction effect $\mathrm{p}=0.052$ ) with 95\% CIs (controlling for variables in Table 3).
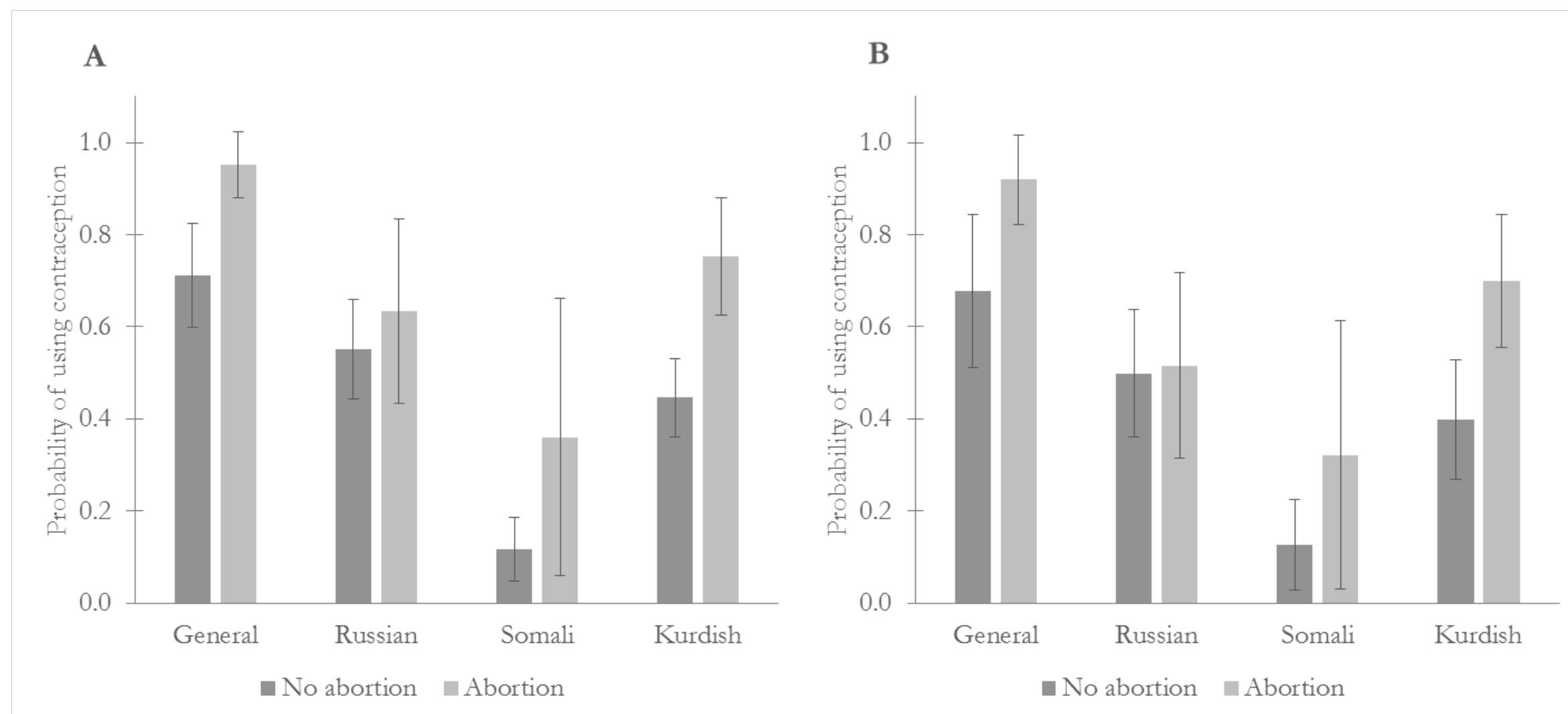


\section{Appendix Methods}

Our model estimates whether having an abortion is associated with current contraceptive use, while controlling for a range of adjustment variables (eq. 1).

$$
\operatorname{logit}\left(\widehat{Y)}=\widehat{\alpha}+\widehat{\beta_{d} D}+\widehat{\beta_{2}} X_{2}+\cdots+\widehat{\beta_{k}} X_{k},\right.
$$

where $D$ is the experience of abortion and $X_{2}-X_{k}$ are the adjustment variables.

This model was weighted using propensity scores to balance the population so that the group who had never had an abortion resembled the group who had, in terms of baseline characteristics preceding the abortion experience. The propensity score is a predicted probability from a logistic regression model, where the baseline characteristics predict the likelihood of having an abortion.

$$
\hat{p}_{i}=\frac{\exp \left(\hat{\alpha}+\widehat{\beta_{b}} x_{b}\right)}{1+\exp \left(\hat{\alpha}+\widehat{\beta_{b}} x_{b}\right)}
$$

where $\hat{p}_{i}$ is the propensity score and $x_{b}$ a vector of the baseline characteristics.

We calculated ATT weights, which leave the group that experienced an abortion unaltered (eq. 3). Those who had never had an abortion were weighted with propensity scores to cancel the selection effect by making the baseline characteristics of this group similar to those of the abortion group (eq. 4).

$$
\begin{gathered}
\text { For } d_{i}=1: w_{i, A T T}=1, \\
\text { For } d_{i}=0: w_{i, A T T}=\frac{\hat{p}_{i}}{1-\hat{p}_{i}}
\end{gathered}
$$


Appendix Table 1. Odds of ever having had an abortion (propensity score model, logistic regression).

\begin{tabular}{ll}
\hline Variable & Odds ratio \\
\hline Cohort 1960s (ref.) & 1.00 \\
Cohort 1970s & 0.89 \\
Cohort 1980s & 0.48 \\
Cohort 1990s & $0.20^{*}$ \\
General population (ref.) & 1.00 \\
Russian & $2.52^{*}$ \\
Somali & 1.86 \\
Kurdish & $4.17^{* *}$ \\
Primary education (ref.) & 1.00 \\
Secondary education & 0.63 \\
General population or other faith (ref.) & 1.00 \\
Muslim & 0.44 \\
General population or migrated before age 16 (ref.) & 1.00 \\
Migrated after age 16 & $0.39 *$ \\
\hline
\end{tabular}

Notes: ${ }^{*} \mathrm{p}<0.05, * * \mathrm{p}<0.01$ 
Appendix Table 2. Balance of the samples: means of explanatory variables in the propensity model by abortion experience.

\begin{tabular}{llll}
\hline Variable & No abortion & Abortion & Difference \\
\hline Original data & & & \\
Cohort 1960s & 0.14 & 0.18 & -0.04 \\
Cohort 1970s & 0.38 & 0.46 & -0.08 \\
Cohort 1980s & 0.38 & 0.31 & 0.07 \\
Cohort 1990s & 0.10 & 0.05 & 0.05 \\
General population & 0.23 & 0.24 & -0.01 \\
Russian & 0.29 & 0.35 & -0.06 \\
Somali & 0.22 & 0.13 & 0.09 \\
Kurdish & 0.26 & 0.29 & -0.03 \\
Secondary education & 0.59 & 0.55 & 0.04 \\
Muslim & 0.42 & 0.29 & 0.14 \\
Migrated after age 16 & 0.54 & 0.53 & 0.01 \\
ATT weighted data & & & \\
Cohort 1960s & 0.18 & 0.18 & 0.00 \\
Cohort 1970s & 0.43 & 0.46 & -0.03 \\
Cohort 1980s & 0.33 & 0.31 & 0.02 \\
Cohort 1990s & 0.05 & 0.05 & 0.00 \\
General population & 0.26 & 0.24 & 0.03 \\
Russian & 0.33 & 0.35 & -0.02 \\
Somali & 0.10 & 0.13 & -0.03 \\
Kurdish & 0.30 & 0.29 & 0.02 \\
Secondary education & 0.57 & 0.55 & 0.02 \\
Muslim & 0.29 & 0.29 & 0.00 \\
Migrated after age 16 & 0.47 & 0.53 & -0.06 \\
\hline
\end{tabular}

